\title{
Electrical and Mechanical Performance of an Enhanced Cable Insulation Scheme for Superconducting Magnets
}

Paolo Fessia, Pier Paolo Granieri, Sebastien Luzieux, Davide Tommasini, Alexandre Gerardin, Michael Guinchard, Federico Regis, Stefano Sgobba, and Aziz Zaghloul

\begin{abstract}
New polyimide cable insulation schemes improving the cooling of $\mathrm{Nb}$-Ti superconducting coils were recently developed to face the severe heat loads at which the next generation of superconducting accelerator magnets will work.

In order to qualify the new insulation, a test campaign was realized to assess both its electrical and mechanical features with respect to the standard LHC insulation. The electrical tests assessed the dielectric strength and inter-turn leakage current to be satisfactory. The mechanical tests investigated the insulation thickness under load and the stress relaxation at ambient temperature, thus providing essential information for the magnetic and mechanical design of the final focusing magnets for the LHC upgrade phase I.
\end{abstract}

Index Terms-LHC upgrade, mechanical and electrical tests, stress relaxation, superconducting magnets cable insulation.

\section{INTRODUCTION}

$\mathbf{T}$ HE LHC phase I upgrade [1], [2] of the interaction regions around CMS and ATLAS requires the replacement of the final triplet, presently made by the MQXA [3] and MQXB [4] 70 $\mathrm{mm}$ aperture quadrupoles built by the US-Japan collaboration, with a new set of quadrupoles MQXC. This set of quadrupoles will use the same $\mathrm{Nb}$-Ti technology and will have a larger aperture and longer length, thus allowing to squeeze the beta function at the collision points $\beta^{*}$ up to $25-30 \mathrm{~cm}$. It is foreseen to use the existing spare cable of the main LHC dipoles (both 01 and 02 cable types [5]) to cope with the tight schedule and to reduce the costs. The increase of luminosity puts a further requirement on the coils to cope with an increased heat deposition [2]. To manage this load it was necessary to develop a new insulation scheme to improve the transparency of the coils to $1.9 \mathrm{~K}$ helium bath and therefore increase the heat transfer coefficient. The new insulation, hereafter referred to as Enhanced Insulation, was proven to be very effective from the thermal point of view improving the capacity of heat removal of a factor of 4-5 with respect to the standard LHC insulation. Its thermal characteristics are presented elsewhere [6], [7]. It is nevertheless important to complete the qualification of this insulation looking at other aspects such as:

- Dielectric strength and leakage current

- Thickness under compression

- Stress relaxation vs. time and peak stress

This paper analyses the above mentioned points describing the experimental set up and discussing the obtained results.

Manuscript received October 19, 2009. First published March 01, 2010; current version published May 28, 2010. This project has received funding from the European Community's Seventh Framework Programme (FP7/2007-2013) under the Grant Agreement no 212114.

Color versions of one or more of the figures in this paper are available online at http://ieeexplore.ieee.org.

Digital Object Identifier 10.1109/TASC.2010.2040470
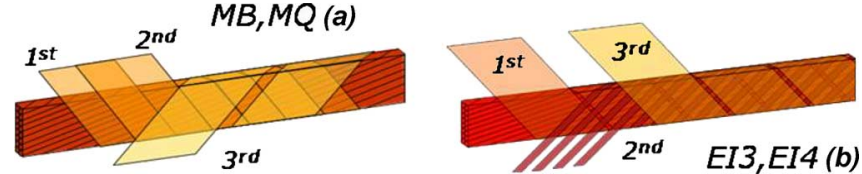

Fig. 1. Scheme of the LHC main dipole (MB)/main quadrupole (MQ) insulations (a), and of the Enhanced Insulation (EI3/EI4) (b).

TABLE I

INSULATION SCHEME PARAMETERS

\begin{tabular}{|c|c|c|c|}
\hline $\begin{array}{c}\text { Insulation } \\
\text { type }\end{array}$ & $1^{\text {st }}$ layer & $2^{\text {nd }}$ layer & $3^{\text {rd }}$ layer \\
\hline MB & $\begin{array}{l}11 \text { mm wide, } \\
\text { no gap, } \\
50 \mu \mathrm{m} \text { thick }\end{array}$ & $\begin{array}{l}11 \mathrm{~mm} \text { wide, no gap, } \\
50 \mu \mathrm{m} \text { thick } \\
50 \% \text { overlap } 1^{\text {st }} \text { layer }\end{array}$ & $\begin{array}{c}9 \mathrm{~mm} \text { wide, } 2 \mathrm{~mm} \text { gap, } \\
69 \mu \mathrm{m} \text { thick, } \\
\text { cross wrapped }\end{array}$ \\
\hline MQ & $\begin{array}{l}11 \text { mm wide, } \\
\text { no gap, } \\
50 \mu \mathrm{m} \text { thick }\end{array}$ & $\begin{array}{l}11 \mathrm{~mm} \text { wide, no gap, } \\
37.5 \mu \mathrm{m} \text { thick } \\
50 \% \text { overlap } 1^{\text {st }} \text { layer }\end{array}$ & $\begin{array}{c}9 \mathrm{~mm} \text { wide, } 2 \mathrm{~mm} \text { gap, } \\
55 \mu \mathrm{m} \text { thick, } \\
\text { cross wrapped }\end{array}$ \\
\hline EI3 & $\begin{array}{l}9 \mathrm{~mm} \text { wide, } \\
1 \mathrm{~mm} \text { gap, } \\
50 \mu \mathrm{m} \text { thick }\end{array}$ & $\begin{array}{c}3 \mathrm{~mm} \text { wide, } 1.5 \mathrm{~mm} \text { gap, } \\
50 \mu \mathrm{m} \text { thick } \\
\text { cross wrapped }\end{array}$ & $\begin{array}{l}9 \mathrm{~mm} \text { wide, } 1 \mathrm{~mm} \text { gap, } \\
69 \mu \mathrm{m} \text { thick, } \\
50 \% \text { overlap } 1^{\text {st }} \text { layer }\end{array}$ \\
\hline EI4 & $\begin{array}{l}9 \mathrm{~mm} \text { wide, } \\
1 \mathrm{~mm} \text { gap, } \\
50 \mu \mathrm{m} \text { thick }\end{array}$ & $\begin{array}{c}3 \mathrm{~mm} \text { wide, } 1.5 \mathrm{~mm} \text { gap, } \\
75 \mu \mathrm{m} \text { thick } \\
\text { cross wrapped }\end{array}$ & $\begin{array}{c}9 \mathrm{~mm} \text { wide, } 1 \mathrm{~mm} \text { gap, } \\
69 \mu \mathrm{m} \text { thick, } \\
50 \% \text { overlap } 1^{\mathrm{st}} \text { layer }\end{array}$ \\
\hline
\end{tabular}

\section{CABle InSUlation}

In this work we will compare the four insulation layouts shown in Fig. 1 and described in Table I. All of them are fully polyimide. The external layer has, on its outer surface, polyimide glue that reacts during the curing cycle. The insulation types mentioned in this article are as follows:

- MB: insulation used for the MB magnets of the LHC. Applied on both cables type 01 and 02 .

- MQ: insulation used for the MQ magnets of the LHC. Applied on cable type 02 only.

- EI3: enhanced insulation developed for this project.

- EI4: enhanced insulation developed for this project with a larger void fraction than EI3.

EI3 and EI4 are the two versions of the enhanced insulation scheme retained from the screening of several new schemes, tested at the beginning of this program.

\section{SAMPLES}

The electrical and mechanical tests were performed using two and ten-unit stacks, respectively: the insulated cables were alternately stacked to compensate for the cable keystone, thus forming a rectangular stack. The length of the cured stack is $170 \mathrm{~mm}$ and two different bonding cycles were used: pressure of either $80 \mathrm{MPa}$ or $130 \mathrm{MPa}$ at $190^{\circ} \mathrm{C}$ respectively. The two 
TABLE II

DiELECTRIC STRENGTH TEST [kV]

\begin{tabular}{cccc}
\hline \hline Insulation type & $1^{\text {st }}$ sample & $2^{\text {nd }}$ sample & $3^{\text {rd }}$ sample \\
MB & 22 & 18 & 22 \\
EI3 & 9 & 12 & 8 \\
EI4 & 14 & 12 & 11 \\
\hline \hline
\end{tabular}

curing pressures were used in order to identify possible effects of this parameter on the final characteristic of the cured stack and they represent a lower and upper limit, respectively. Both cable type 01 and 02 were used. Cable 02 is more compacted than cable 01 and the two cables constitute different substrate to the insulation affecting its final behavior.

\section{Electrical MeAsurements}

The tests were performed on two-unit stacks made of cable 01 , cured in air at $130 \mathrm{MPa}$ and $190^{\circ} \mathrm{C}$. The samples are $170 \mathrm{~mm}$ long, pressed over $113 \mathrm{~mm}$. Measurements of the inter-turn leakage current were performed two minutes after the voltage application at different compressive pressures of 50,100 and $150 \mathrm{MPa}$, applying voltages of 1,3 and $5 \mathrm{kV}$. The results show no striking differences among the three types of insulation, and no significant dependence on the applied pressure. The leakage current is always extremely small, one or two orders of magnitude lower than $1 \mathrm{nA}$ in all cases.

Measurements of dielectric strength were performed under a compression of $80 \mathrm{MPa}$ and the tests were repeated three times. The results are reported in Table II. The new insulation results to be weaker than the standard MB insulation. However the dielectric strength of all the insulation schemes is orders of magnitude higher than the inter-turn voltage arising in case of a quench $(100 \mathrm{~V})$. Hence the enhanced insulation fulfills the required criteria of dielectric strength. It is worth mentioning that in all cases the discharge took place outside the compressed area, in a region of mechanical discontinuity, meaning that the experimental results are a conservative minimum.

\section{INSULATION THICKNESS MEASUREMENTS}

The insulation thickness is an important parameter to be accounted for in the magnetic and mechanical design of the magnet. It was measured, after curing, as a function of the compression stress up to a peak of $100 \mathrm{MPa}$, both on the loading and unloading branch of the third cycle [8]. Table III reports the values measured at $50 \mathrm{MPa}$ compression on the unloading branch of the stress-strain curve. It can be remarked that:

- As expected, due the higher compaction of the cable 02, the loss in thickness between the theoretical thickness and the measured one is lower for cable 02 than for cable 01 (about 5-10 $\mu \mathrm{m}$ ).

- The loss in thickness is higher for samples cured at $130 \mathrm{MPa}$ vs. samples cured at $80 \mathrm{MPa}$ (about 2-4 $\mu \mathrm{m}$ ).

- The loss in thickness for the enhanced insulation is higher than for the traditional insulation $(45 \mu \mathrm{m}$ with respect to $30 \mu \mathrm{m})$. This is linked to the presence of a higher void fraction and to the higher peak stresses originated at the crossing of the different insulation layers.
TABLE III

MEASURED INSULATION THICKNESS

\begin{tabular}{ccccc}
\hline \hline $\begin{array}{c}\text { Insulation } \\
\text { scheme }\end{array}$ & $\begin{array}{c}\text { Cable } \\
\text { type }\end{array}$ & $\begin{array}{c}\text { Curing } \\
\text { Pressure } \\
{[\mathrm{MPa}]}\end{array}$ & $\begin{array}{c}\text { Geometrical } \\
\text { insulation } \\
\text { thickness }[\mu \mathrm{m}]\end{array}$ & $\begin{array}{c}\text { Measured } \\
\text { Insulation } \\
\text { Thickness }[\mu \mathrm{m}]\end{array}$ \\
MB & 01 & 80 & 169 & 138 \\
MB & 01 & 130 & 169 & 130 \\
MB & 02 & 80 & 169 & 140 \\
MB & 02 & 130 & 169 & 136 \\
MQ & 01 & 80 & 142.5 & 109 \\
MQ & 01 & 130 & 142.5 & 106 \\
MQ & 02 & 80 & 142.5 & 115 \\
MQ & 02 & 130 & 142.5 & 113 \\
EI3 & 01 & 80 & 169 & 120 \\
EI3 & 01 & 130 & 169 & 116 \\
EI3 & 02 & 80 & 169 & 129 \\
EI3 & 02 & 130 & 169 & 125 \\
EI4 & 01 & 80 & 194 & 139 \\
EI4 & 01 & 130 & 194 & 134 \\
EI4 & 02 & 80 & 194 & 144 \\
EI4 & 02 & 130 & 194 & \\
\hline \hline
\end{tabular}

\section{Stress Relaxation MeASUREMENTS}

The aim of this test campaign was to compare the profile of stress losses on the cable stacks due to the polyimide creep. The knowledge of the stress loss is needed to set the collaring load, in order to obtain the desired pre-stress on the magnet after storage. This parameter has therefore an impact on the magnet and mechanical design and on the assembly tooling.

A test set up was designed and built as shown in Fig. 2. The force was applied on two series of four bolts and the pressure was measured via five pairs of mechanically independent strain gauges over a length of $80 \mathrm{~mm}$. Continuous data acquisition of the five pairs was performed. Fig. 3 shows a typical curve of stress measurement as a function of time. The largest loss takes place during the initial 10 days after the application of the force. Further $3 \%$ of the initial pressure is lost in the following five weeks, and further $3 \%$ would be lost for week 10 . We can conclude that measurements up to ten days duration provide good indication of the global stress relaxation behavior, allowing a comparison among different insulation schemes. Further measurements will be performed up to 5-6 months to appreciate the asymptotic behavior.

Table IV provides the percentage losses for the MB and EI4 insulation for three different initial peak stresses $p_{\max }$. Measurements refer to cable type 01 . It is important to remark that the percentage losses are quite constant with respect to the initial peak pressure. This important feature allows scaling losses to the same peak stress for tests that did not undergo the same initial pressure. Scaling was performed among measurements that took place in a range of maximum $20 \mathrm{MPa}$.

In Fig. 4 we compare the losses for the MB, EI3 and EI4 insulation schemes for cable type 01 , normalized to an initial pressure of $120 \mathrm{MPa}$. It is possible to observe that: 


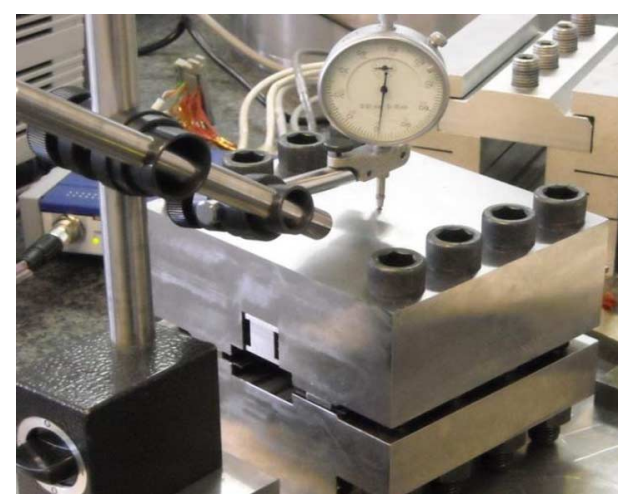

Fig. 2. Experimental set up for stress relaxation measurements.

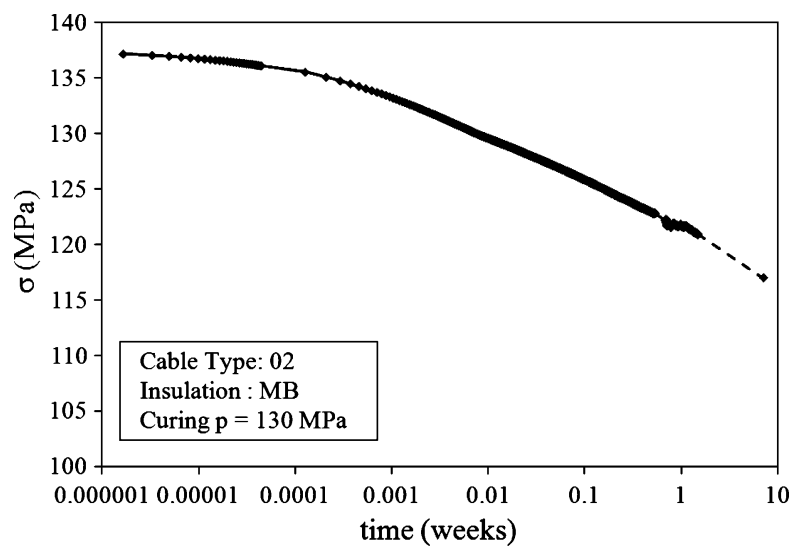

Fig. 3. Stress profile vs. time. Data have been taken up to $\sim 10$ weeks.

TABLE IV

StRESS RELAXATION AS A FUnCTION OF $P_{\max }$

\begin{tabular}{ccccc}
\hline \hline $\begin{array}{c}\text { Insulation } \\
\text { type }\end{array}$ & $\begin{array}{c}\mathrm{p}_{\max } \\
(\mathrm{MPa})\end{array}$ & $\begin{array}{c}\Delta \mathrm{p} / \mathrm{p}_{\max } \\
1 \text { day (\%) }\end{array}$ & $\begin{array}{c}\Delta \mathrm{p} / \mathrm{p}_{\max } \\
5 \text { days (\%) }\end{array}$ & $\begin{array}{c}\Delta \mathrm{p} / \mathrm{p}_{\max } \\
10 \text { days (\%) }\end{array}$ \\
\hline MB & 96 & 21 & 24 & 25 \\
MB & 118 & 23 & 27 & 28 \\
MB & 130 & 22 & 25 & 27 \\
EI4 & 96 & 19 & 22 & 25 \\
EI4 & 121 & 23 & 26 & 26 \\
EI4 & 130 & 20 & 23 & 24 \\
\hline \hline
\end{tabular}

1) Maximum losses after 10 days vary between $24 \mathrm{MPa}$ and $33 \mathrm{MPa}$, therefore in a quite narrow band.

2) The EI3, which uses a thinner intermediate polyimide layer to create void channels, presents smaller losses than the EI4 that has a larger void fraction. The MB insulation presents larger losses then all the other schemes even if it is more compact. The experiment was repeated using a completely new sample stack and the results of the second experiment confirmed the preliminary ones.

In Fig. 5 we report the losses for the cable type 02. While the losses for the enhanced insulation are very similar to the ones recorded on the cable 01 , for the MB the situation is drastically different showing much smaller values. This behavior could be explained if we consider two different dominant mechanisms of stress relaxation:

1) The first takes place at the interface between the superconducting cable and the first layer of insulation and is linked

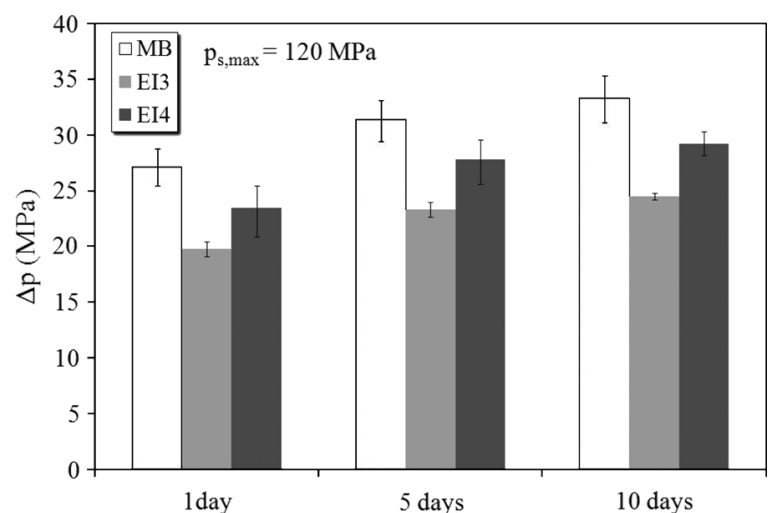

Fig. 4. Stress losses with an initial 120 MPa peak pressure for the MB, EI3 and EI4 insulation schemes. Data are scaled to $120 \mathrm{MPa}$. Original initial peak pressure: $122 \mathrm{MPa}$ for MB, $120 \mathrm{MPa}$ for EI4, $107 \mathrm{MPa}$ for EI3. Insulation applied on cable 01 .

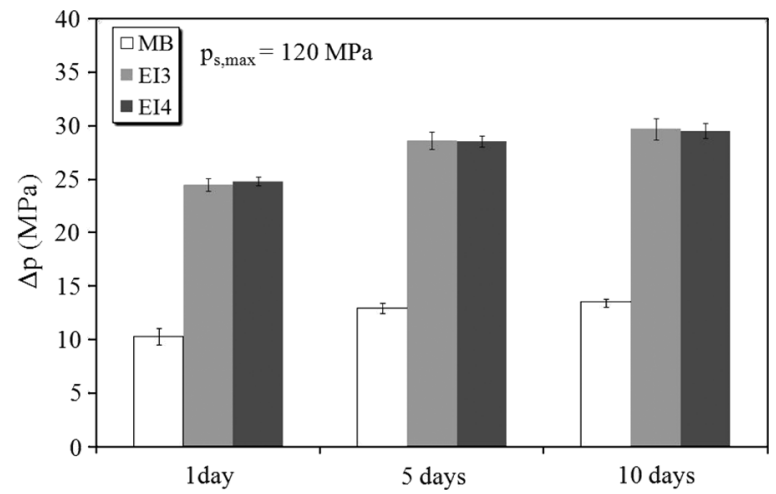

Fig. 5. Stress losses with an initial $120 \mathrm{MPa}$ peak pressure for the MB and EI4 insulation schemes. MB and EI3 scaled from $140 \mathrm{MPa}$. Insulation applied on cable 02 .

to the viscoplastic deformation of the material among the cable strands. This phenomenon seems to be dominant for the MB insulation: placed on a more compact substrate (cable 02) it shows lower stress losses.

2) The second takes places between layers and is linked to the stress concentration on the edges of the insulation tape. This is characteristic of the interfaces and contacts around the discontinuous intermediate layer of the enhanced insulations and it seems to be dominant for these schemes. This is also confirmed by the fact that the change of the void fraction in the insulation by only changing the thickness of the 2nd layer does not strongly modify the stress relaxation behavior (EI3 vs. EI4).

Note that for the measurements on cable 02 the peak stress for MB and EI4 was $140 \mathrm{MPa}$ and the data were scaled down to be coherent with the measurements shown for cable 01 .

More tests on the stress relaxation are planned, mainly at lower initial pressure (80 MPa).

The influence of the curing pressure $p_{c}$ on the stress relaxation was preliminarily investigated for the EI3 scheme wrapped on cable type 02. It can be seen in Table $\mathrm{V}$ that a higher curing pressure helps stabilizing the cable, pre-creeping the stack during curing. This could bring to prefer higher curing pressure in order to stabilize the coils.

The use of a collar structure makes it very probable that coils will be submitted to higher pre-stress during the collaring 
TABLE V

INFLUENCE OF CURING PRESSURE $p_{c}$

\begin{tabular}{cccc}
\hline \hline & Elapsed time & $\begin{array}{c}\Delta \mathrm{p}[\mathrm{MPa}] \\
p_{c}=80 \mathrm{MPa}\end{array}$ & $\begin{array}{c}\Delta \mathrm{p}[\mathrm{MPa}] \\
p_{c}=130 \mathrm{MPa}\end{array}$ \\
\cline { 2 - 4 } Cable 02 & 1 day & 25 & 21 \\
Insulation EI3 & 5 days & 29 & 25 \\
& 10 days & 31 & 24 \\
\hline \hline
\end{tabular}

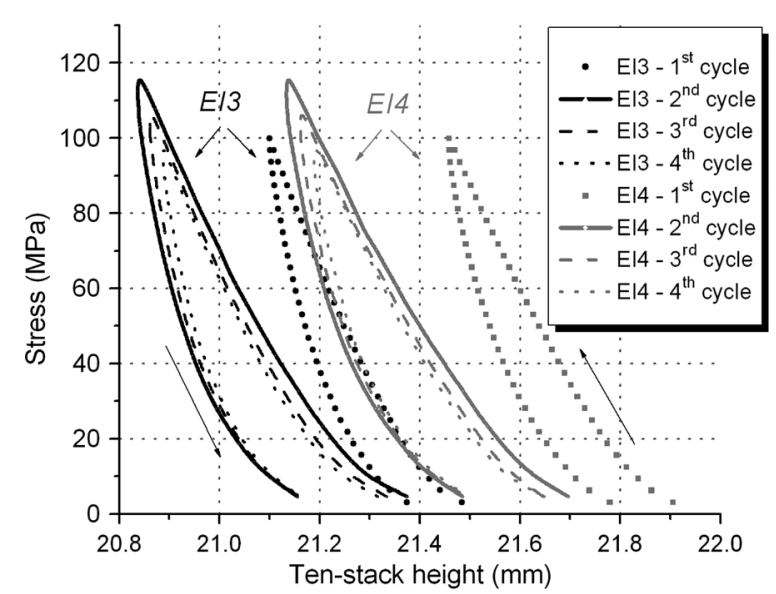

Fig. 6. Effect of the cycle peak pressure on the height of the ten-unit stack. EI3 and EI4 insulations were applied on cable 01, cured at $130 \mathrm{MPa}$.

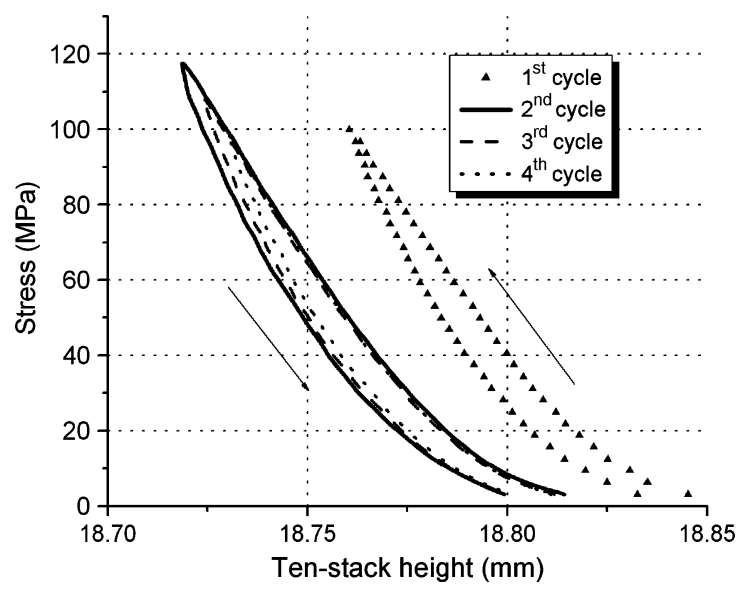

Fig. 7. Effect of the cycle peak pressure on the height of the ten-unit stack. Stack made of type 01 bare cables, cured at $130 \mathrm{MPa}$.

process with respect to those at which they will be stored and from which the stress relaxation will start. We wanted therefore to investigate the effect of this kind of cycle from the stress relaxation point of view. The following testing sequence was adopted to simulate the coil life:

1) 3 cycles up to $100 \mathrm{MPa}$, the last of which is reported as $1 \mathrm{st}$ cycle in Figs. 6 and 7.

2) 3 cycles up to $120 \mathrm{MPa}$, the last of which is reported as $2 \mathrm{nd}$ cycle in Figs. 6 and 7.

3) 1 cycle up to $110 \mathrm{MPa}$ and 1 cycle up to $100 \mathrm{MPa}$, reported in Figs. 6 and 7 as 3rd and 4th cycle, respectively.

Two "preliminary" cycles were performed every time the peak stress was exceeded. They are needed for the mechanical training of the sample. Fig. 6 reports the results for the EI3 and EI4. Similar results were found for the MB insulation [8]. We can remark that:
1) The stress - strain curve is stable (after at least two training cycles) if the peak stress is not exceeded. If this happens a "plastic" shift takes place (as from 1st to 2nd cycle).

2) If the cycle is performed up to a maximum stress that does not exceed the peak stress, the loading branches of the different cycles nearly superpose (as from 2nd to 3rd cycle, and from 3rd to 4 th cycle).

The same cycle was applied on a cured stack of bare cables. Results are reported in Fig. 7. All the features shown in Fig. 6 are present including the shift between the 1st and the other cycles. On the other hand the shift is smaller. The amplitude of the hysteresis cycle, which is a measurement of the power dissipation, is also smaller. It can be concluded that the friction among strands plays an important role in the stack behavior, amplified by the presence of insulation.

\section{CONCLUSIONS}

A new insulation scheme that allows improving the cooling of $\mathrm{Nb}$-Ti superconducting coils was qualified from the electrical and mechanical point of view.

The electrical robustness of the proposed insulation proved to be satisfactory in the tests performed on cables stacks. Tests on real coil are now required, in particular to assess the stability during winding in the head of $\cos \theta$ magnets.

The mechanical tests addressed different aspects of the insulation. The thickness measurements showed that the two considered versions of the new insulation feature a larger decrease in thickness during the curing cycles with respect to the LHC standard insulations. As for the stress relaxation tests, the behavior of the enhanced insulation is similar to the standard MB insulation for the type 01 cable, whereas it presents larger relaxation when applied on the type 02 cable. In the tested range the initial peak stress does not show to have an impact on the relative loss of stress after a fixed interval of time. On the contrary, the curing pressure has an influence, both on the final insulation thickness and on the loss of stress. Finally it was shown that the peak stress seen by the coil during its life is a key parameter in setting its working point. All these tests allowed quantifying important parameters that must be accounted for during magnetic and mechanical design of the final focusing magnets for the LHC upgrade phase I.

\section{REFERENCES}

[1] J. P. Koutchouk, L. Rossi, and E. Todesco, A Solution for Phase-One Upgrade of the LHC Low-Beta Quadrupoles Based on Nb-Ti CERN, Geneva, Switzerland, LHC Project Report 1000, 2007.

[2] R. Ostojic et al., Conceptual Design of the LHC Interaction Region Upgrade: Phase-I CERN, Geneva, Switzerland, LHC Project Report 1163,2008

[3] Y. Ajima et al., Nucl. Instrum. Meth. A, vol. 550, p. 499, 2005.

[4] M. Lamm et al., in European Particle Accelerator Conference, 2006, p. 2637.

[5] O. Bruning et al., LHC Design Report vol. 1 CERN, Geneva, Switzerland, 2004, p. 157.

[6] P. P. Granieri et al., "Heat transfer in an enhanced cable insulation scheme for the superconducting magnets of the LHC luminosity upgrade," IEEE Trans. Appl. Supercond., submitted for publication.

[7] P. Fessia et al., "A $120 \mathrm{~mm}$ Bore quadrupole for the phase I LHC upgrade," IEEE Trans. Appl. Supercond., submitted for publication.

[8] P. P. Granieri, Mechanical Measurements at Ambient Temperature in an Enhanced Cable Insulation Scheme for the Superconducting Magnets of the LHC Luminosity Upgrade CERN internal note, to be published. 